\title{
GOVERNMENT INCENTIVE MECHANISM OF CLOSED-LOOP SUPPLY CHAIN BASED ON INFORMATION ASYMMETRY
}

\author{
Qunli Wu, Xinxin Xu* And Ronghao Line
}

\begin{abstract}
Focusing on the closed-loop supply chain (CLSC) comprising the manufacturer, retailer, and consumers in the waste products market, this study investigates how the government addresses the adverse selection problem on the hidden recovery costs of retailer and how it manages the moral hazard problem on the level of retailer's hidden efforts. Based on incentive theory, a government incentive regulation aiming at maximizing social welfare is established in this study. In addition, a list of contracts with transfer payments is presented to elucidate the retailer' collection efficiency and motivate the retailer to make the optimal investment. Besides, the impact of related factors on the recovery cost and social welfare level using numerical simulations is validated. Under government regulation, the retailer could maximize profit only by reporting the true recovery technology-type information to the government. Moreover, the retailer with high-recovery efficiency could obtain both retained profit and additional information rent. Finally, as the retailer made efforts to increase the recovery level, it increased investment cost, which affected the enthusiasm of enhancing the retailer's recovery efficiency. Thus, the government should not blindly pursue the enhancement of recycling efficiency regardless of the cost, but should focus more on the control of recycling equipment and technology cost. Overall, this study facilitates scientific policy development and provides a reference for promoting CLSC operations.
\end{abstract}

Mathematics Subject Classification. 90B06.

Received May 12, 2020. Accepted August 8, 2021.

\section{INTRODUCTION}

The rapid growth of information globalization and science and technology has inevitably harmed the human living environment. With the improvement of environmental awareness, people are seeking better living environment, they are calling for a green circular economy [8,9,11]. Countries around the globe started adopting various policies, laws, and regulations, focusing more on the reverse supply chain operation, especially the closed-loop supply chain (CLSC) based on remanufacturing. For example, in China, the national government regulated the "Administration of Recycling and Treatment of Waste Electrical and Electronic Equipment" (WEEE) in 2009. As televisions, washing machines, refrigerators, air conditioners, and computers account for the most significant proportion of all waste of electrical appliances, recycling of the above waste equipment is included in the first batch of the recycling catalog. As the government considers recycling waste products significant, companies' requirements are also increasing gradually $[14,17,32,48]$. Meanwhile, under the pressure of national laws,

Keywords. Adverse selection, moral hazard, Closed-loop supply chain, government incentive regulation model, game model.

Department of Economic Management, North China Electric Power University, Baoding 071100, P.R. China.

*Corresponding author: 1767896589@qq.com 
regulations, and some environmental protection policies, the proper treatment of recycling and remanufacturing not only decrease the costs and increase the profit but also enhance a company's reputation and augment its social responsibility. Thus, many companies focus on recycling and on remanufacturing waste products $[1,18]$.

Because of the importance of recycling waste products, many scholars have studied CLSC. The early studies involved multiple fields, including the structure design of CLSC, asymmetric information, and the government incentive regulation. Here we only review the literature that is relevant to this paper. There are two reasons why companies choose to develop recycling activities: improvement of public awareness of environmental protection, and government's incentive measures, which encourage companies to develop profitable recycling activities. See $[3,5,6,21,30,34,38]$ for examples. Based on a game theory perspective, Moorthy [25] established a two-stage Stackelberg game model to study the impact of cost and price competitions on product decisions. To reduce environmental pollution and production costs, Guide and Wassenhove [15] developed a game framework to analyze recycling activities' profitability. Xiong et al. [41] built a two-level game model to investigate the CLSC decisions when the dealers engage in remanufacturing activities. Savaskan et al. [28] studied the CLSC from two aspects: recycling channels and pricing of waste products. Mukhopadhyay et al. [26] used the Stackelberg game to study the problem of supply chain coordination when the retailer's cost information is asymmetric. According to the incentive contract designed by the supplier in the supply chain, the supplier can promote the retailer to reported the true cost information. Then, they compared the optimal effort and information rent under two different contracts. Liu et al. [23] examined how to solve the information asymmetry in a three-level supply chain composed a retailer and two competing manufacturers, which the cost of the retailer is the private information. Wu et al. [39] designed a buyback contract to perfectly coordinate a CLSC under information asymmetry. Finally, Shekarian [29] reviewed and summarized the factors affecting CLSC models.

However, the above references mainly studied the problem of "single" information asymmetry, and only considered moral hazard/adverse selection. In the CLSC system, information asymmetry exists not only before signing the contract, which we call adverse selection, but also after signing the contract,which we call a moral hazard. Given the limitations of the above research, Tian and Liu [31] analyzed how to distinguish a salesperson's value to the enterprise when they did not know its ability and effort. They gave a double objective linear contract based on the mixed incentive model, and the optimal contract was obtained by solving and describing the model. Zhang and Luo [44] studied the coordination problem of credit transaction supply chain under bilateral information asymmetry. They concluded that the manufacturer could increase the order quantity of sellers by using credit transactions. When the manufacturer and seller have private information simultaneously, establishing a bilateral auction model can obtain the best credit period. Pal and Saha [27] investigated the problem of adverse selection and moral hazard in the two-stage supply chain due to the difference of supply chain structure and information asymmetry. Xu et al. [42] constructed an incentive regulation model and considered the recycler's investment under the condition that the recycler's recovery ability and effort can not be observed. Yu and Jin [43] established an optimal return strategy model of supplier when facing the fuzzy market demand and the retailer's private information of market price, which can motivate retailer to provide the optimal order quantity to improve the overall performance of the supply chain. Liu and Song [22] considered how to design an outsourcing screening contract, including two parameters of a fixed payment and profit-sharing coefficient in the process of innovative product research and development to stimulate the contractor's initial optimal effort. Finally, Wang et al. [35] constructed the incentive model of CLSC under the principal-agent framework to analyze the problem of how the remanufacturer designs an incentive model to guide the recycler to make an effort under the condition of dual information asymmetry. Some of the above scholars have considered the problems of moral hazard and adverse selection, however, they did not consider the leading role of the government in carrying out environmental protection activities in the supply chain. Therefore, in our research, we investigate the effects of government incentive regulation on the decisions of CLSC players.

Under the pressure of environmental protection, the governments attach great importance to the recycling of waste products. However, due to the higher recovery cost, the companies can not improve the recovery efficiency. At this time, the government participates in the enterprise recycling activities in various ways $[10,19,27,33,36]$ applied the principal-agent theory to study the CLSC model with the information asymmetry 
and the government's reward. They were applying the information screen contract to obtain the true information of the manufacturer's effort level of recovery. Zhang and Jing [45] solved the pricing mechanism problem in the transmission and distribution market according to the government incentive regulation model. Wang et al. [37] investigated the effects of the government policies on the optimal decisions of the CLSC players. The results show that the tax/subsidy policies of the government play an active role in improving the recovery efficiency, and the government subsidies to different players have different effects on the optimal decision-making of CLSC. Li et al. [20] used game theory to study asymmetric information on differential pricing of CLSC with the government regulation. Then, Zhang et al. [47] studied how the government develops an incentive measure to promote the carbon emissions of a power plant. Wu et al. [39] proposed a low-carbon incentive model for an online shopping supply chain based on online stores and their suppliers. Finally, Atasu et al. [2] considered the dual effects of economy and environment and established the game model among the government, manufacturer, and consumer. The government gave a subsidy to the manufacturers and guided them to recycle and remanufacturer the waste products, and discussed the conditions for effective legislation in the end. Although the above studies consider the government intervention to the CLSC players, few studies build the government incentive regulation model considering moral hazard and adverse selection simultaneously. See Table 1 for a detailed literature survey.

Therefore, this paper applies incentive theory to consider a CLSC composed of manufacturer, retailer, and consumers under government incentive regulation, and to study the problem of dual information asymmetry with both the recovery cost and effort are the private information of the retailer. The government designs a regulation mechanism, which would disclose the retailer's true recovery cost. Then the government would reimburse the retailer to encourage to improve the recovery effort and reduce the recovery cost. At the end of the paper, we calculate the rate of recovery specified by the government for the retailer. An incentive regulation model is established to answer the following questions:

- How to reveal the retailer's true reverse cost information and reduce the impact of asymmetric information on the operation of CLSC?

- How to guide the retailer to invest reasonably and improve the recovery efficiency?

- How the government makes the optimal contract to encourage the retailer and maximizes social welfare?

In summary, this paper has three main contributions: (1) It extends the CLSC decisions making from an information symmetry environment to a dual-information asymmetry environ- ment. (2) It assumes that the government implements a financial reward and punishment mechanism for the retailer with the retailer's information asymmetry. (3) Different from previous research methods, the government incentive regulation theory is applied in this paper to solve the information asymmetry problem of retailer in CLSC. Our work can reference the study of how to make a reasonable investment of companies under government regulation and help the government to design contract programs scientifically in real life according to specific incentive objects.

The paper is structured as follows. In Section 2, the assumptions, notations, models, and solution procedures are described. Section 3 presents numerical example and the parametric analysis. Section 4 outlines the conclusions and future research suggestions.

\section{MODELS}

\subsection{Problem description}

This research considers a CLSC composed of a manufacturer, a retailer, and consumers. the structure of the CLSC is shown in Figure 1. In this CLSC, the manufacturer is responsible for producing products with new and recycled materials and wholesales the products to the retailer. The wholesale prices of new products and remanufactured products set by the manufacturer are $w_{n}$ and $w_{r}$ respectively. The retailer is responsible for selling new and remanufactured products to consumers at the price $p_{n}$ and $p_{r}$. The demand for now products is $D_{n}$ and for remanufactured products is $D_{r}$. The quantity of recycled waste products collected by retailer is $\Omega$, and the retailer buys the collected waste products from consumers at the price $\eta_{r}$, then, the manufacturer purchase the waste products from retailer at the price $\eta_{m}$. The government formulates an incentive mechanism 
TABLE 1. The related studies on CLSC models.

\begin{tabular}{|c|c|c|c|c|c|}
\hline $\begin{array}{l}\text { Review } \\
\text { paper }\end{array}$ & $\begin{array}{l}\text { Government } \\
\text { policy }\end{array}$ & Area & $\begin{array}{l}\text { The information among the } \\
\text { game payers }\end{array}$ & Model & Main contribution \\
\hline$[15]$ & & & Information symmetry & & $\begin{array}{l}\text { Managing product returns for remanu- } \\
\text { facturing }\end{array}$ \\
\hline$[4]$ & & & Dual information asymmetry & $\begin{array}{l}\text { Game } \\
\text { model }\end{array}$ & $\begin{array}{l}\text { Analyzing pork production quality } \\
\text { incentive in supply chain }\end{array}$ \\
\hline$[2]$ & $\begin{array}{l}\text { Setting the } \\
\text { threshold }\end{array}$ & & Information symmetry & & Analyzing effective recycling legislation \\
\hline$[26]$ & & & Single information asymmetry & $\begin{array}{l}\text { Game } \\
\text { model }\end{array}$ & $\begin{array}{l}\text { Designing contracts to motivate } \\
\text { retailer to improve the effort }\end{array}$ \\
\hline$[44]$ & & & $\begin{array}{l}\text { Information symmetry and sin- } \\
\text { gle information asymmetry }\end{array}$ & $\begin{array}{l}\text { Game } \\
\text { model }\end{array}$ & $\begin{array}{l}\text { Establishing coordination mechanism } \\
\text { of CLSC }\end{array}$ \\
\hline [31] & & & Dual information asymmetry & $\begin{array}{l}\text { Incentive } \\
\text { model }\end{array}$ & $\begin{array}{l}\text { Analyzing the dual-objective incentive } \\
\text { model }\end{array}$ \\
\hline [41] & & CLSC & Information symmetry & $\begin{array}{l}\text { Game } \\
\text { model }\end{array}$ & $\begin{array}{l}\text { CLSC considering the distributor par- } \\
\text { ticipation }\end{array}$ \\
\hline [43] & & & $\begin{array}{l}\text { Information symmetry and sin- } \\
\text { gle information asymmetry }\end{array}$ & & $\begin{array}{l}\text { Researching the return strategies with } \\
\text { asymmetric information }\end{array}$ \\
\hline$[42]$ & & CLSC & Dual information asymmetry & & Research on principal-agent theory \\
\hline [39] & & CLSC & Single information asymmetry & $\begin{array}{l}\text { Game } \\
\text { model }\end{array}$ & Analyzing the buy back contract \\
\hline$[22]$ & & & Single information asymmetry & $\begin{array}{l}\text { Game } \\
\text { model }\end{array}$ & $\begin{array}{l}\text { Designing for innovative product } R \& D \\
\text { outsourcing }\end{array}$ \\
\hline [35] & & CLSC & Dual information asymmetry & $\begin{array}{l}\text { Game } \\
\text { model }\end{array}$ & $\begin{array}{l}\text { Analyzing CLSC decision making with } \\
\text { information asymmetry }\end{array}$ \\
\hline [45] & Tax/Subsidy & & Dual information asymmetry & $\begin{array}{l}\text { Incentive } \\
\text { model }\end{array}$ & $\begin{array}{l}\text { Research on government incentive reg- } \\
\text { ulation in transmission and distribu- } \\
\text { tion market }\end{array}$ \\
\hline [23] & & & $\begin{array}{l}\text { Information symmetry and sin- } \\
\text { gle information asymmetry }\end{array}$ & $\begin{array}{l}\text { Game } \\
\text { model }\end{array}$ & $\begin{array}{l}\text { Researching SC contract design with } \\
\text { uncertain information }\end{array}$ \\
\hline$[20]$ & Tax/Subsidy & CLSC & Single information asymmetry & $\begin{array}{l}\text { Game } \\
\text { model }\end{array}$ & $\begin{array}{l}\text { Researching the pricing decision of } \\
\text { CLSC }\end{array}$ \\
\hline$[37]$ & Tax/Subsidy & CLSC & Information symmetry & $\begin{array}{l}\text { Game } \\
\text { model }\end{array}$ & $\begin{array}{l}\text { Analyzing the reward-penalty mecha- } \\
\text { nism of government }\end{array}$ \\
\hline$[40]$ & $\begin{array}{l}\text { Tax/Subsidy } \\
\text { and setting the } \\
\text { threshold }\end{array}$ & & & $\begin{array}{l}\text { Incentive } \\
\text { model }\end{array}$ & $\begin{array}{l}\text { Research on the low carbon incentive } \\
\text { for online shopping SC }\end{array}$ \\
\hline$[47]$ & Tax/Subsidy & & Dual information asymmetry & $\begin{array}{l}\text { Incentive } \\
\text { model }\end{array}$ & $\begin{array}{l}\text { Analysis of government regulation on } \\
\text { power companies }\end{array}$ \\
\hline $\begin{array}{l}\text { This } \\
\text { paper }\end{array}$ & $\begin{array}{l}\text { Tax/Subsidy } \\
\text { and setting the } \\
\text { threshold }\end{array}$ & CLSC & Dual information asymmetry & $\begin{array}{l}\text { Game } \\
\text { model } \\
\text { and } \\
\text { incentive } \\
\text { model }\end{array}$ & $\begin{array}{l}\text { Solving the dual information asymme- } \\
\text { try between the government and the } \\
\text { supply chain players and promotes the } \\
\text { retailer to make reasonable investments }\end{array}$ \\
\hline
\end{tabular}

$t$ to the retailer and leads the whole supply chain system. When the government cannot obtain the retailer's real recovery cost, the government's optimal incentive mechanism would make the retailer reports the true information. It will also encourage the retailer to improve the recovery efficiency after signing the contract and reducing the recovery cost. Therefore, how to develop a suitable incentive mechanism is discussed in this study. The game sequence is shown in Figure 2.

\subsection{Symbol description}

This section defines the fundamental constants and symbols involved in the models shown in Table 2 . 

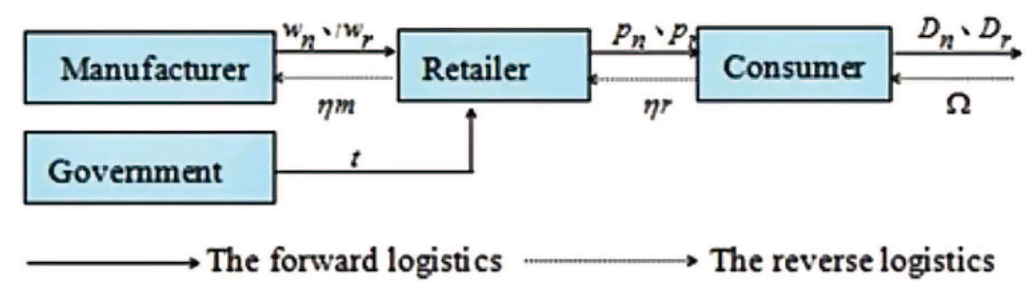

Figure 1. The structure of the closed-loop supply chain.

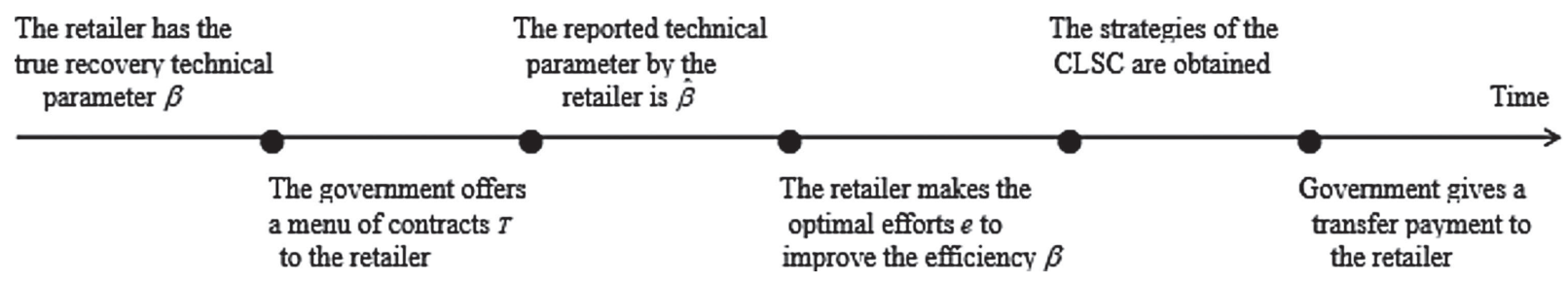

Figure 2. Game sequence.

\subsection{Assumptions}

Assumption 2.1. The CLSC only considers the single-cycle, and both players are risk-neutral. The government takes the maximization of social welfare as the incentive regulation goal, and the players of CLSC take the maximization of profit as the decision-making goal.

Assumption 2.2. As in [45], the recovery cost $\beta$ of the retailer is private information, which the government cannot observe and can be reduced by effort e, such as updating the recycling equipment and increasing the investments in RED of recycling technolo- gies, and the effort cost is $\varphi_{(}(e)$. Therefore, the recovery cost of the retailer with effort is:

$$
c=\beta-e
$$

where $\beta \in(\beta, \bar{\beta})$, a high $\beta$ value signals an inefficient recycling technical level. The probability density and probability distribution functions are $f(\beta)$ and $F(\beta)$ respectively when $\beta \in(\beta, \bar{\beta})$, such that $f(\beta)>0$. The monotone hazard rate $\frac{\mathrm{d}(F(\beta) / f(\beta))}{\mathrm{d} \beta} \geq 0$. Most distributions, such as the normal and exponential meet the condition of the effort made by retailer is the moral hazard coefficient, and related to the retailer's recovery cost, which is also to say that $e=e(\beta)$. In addition, the effort cost is an increasing function on the effort made by the retailer, thus when the effort $e>0$, the $\phi^{\prime}>0$ and the increasing speed satisfies $\phi^{\prime \prime}>0, \phi^{\prime \prime \prime} \geq 0$. It also satisfies $\phi(0)=0$, and when the effort $e \rightarrow \beta$, the effort cost $\phi(e)=+\infty$.

Assumption 2.3. For the manufacturer, the unit production cost of new and remanufactured products are $c_{n}$ and $c_{r}$, such that $c_{n}>c_{r}$. Assume that $c_{r}=\theta c_{n}$, where $\theta$ is the cost-saving rate of the remanufacturing. The smaller $\theta$ the higher the remanufacturing technology, and the larger costs' savings.

Assumption 2.4. The final new and remanufactured products face a common consumer group. The maximum demand of the final new and remanufactured products in the common consumption market is $\alpha$. Because new and remanufactured products are identical, therefore, they substitute each other and the substitution coefficient is $\gamma$. In addition, a differential pricing strategy is implemented between the new and the remanufactured products, which will make the consumers have different preferences for the new and the remanufactured products and result in different price sensitivity to the two types of products. The coefficients of price sensitivity areb ${ }_{n}, b_{r}$. Combined with the above analysis and the market demand function form of duopoly competition in microeconomics, we 
TABLE 2. Symbols and notations.

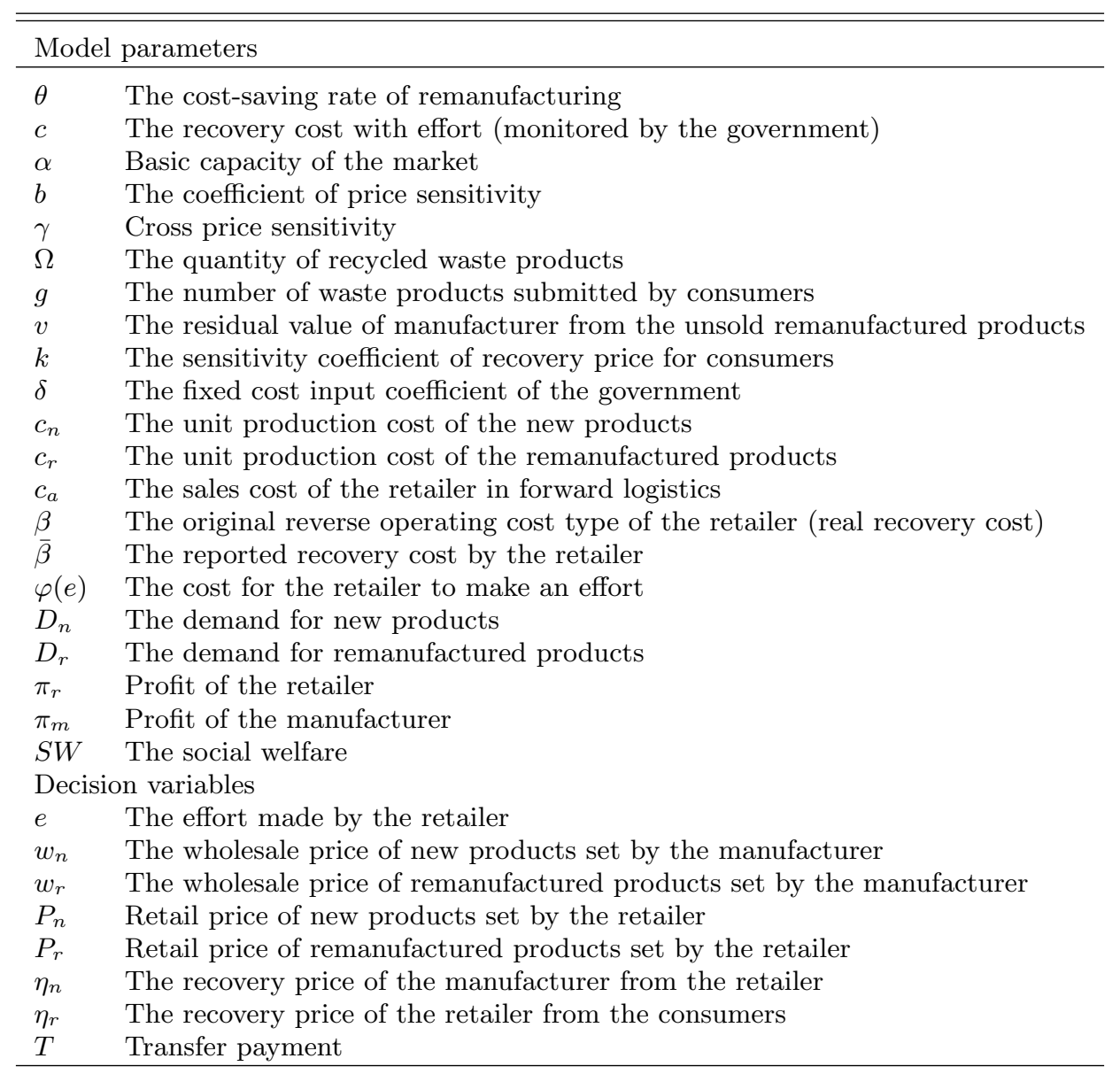

assume that the market demand functions of new and remanufactured products are $D_{n}=\alpha-n_{n} P_{n}+\gamma P_{r}$ and $D_{r}=\alpha-b_{r} p_{R}+\gamma P_{n}$ [7, 24, 28]. Without any loss of generality and as in [12, 20, 46], we make the coefficients of $b_{n}=b_{r}=b$. Thus, the demand functions of the new and remanufactured products are $D_{n}=\alpha-b p_{n}+\gamma p_{r}$ and $D_{r}=\alpha-b_{r} p_{r}+\gamma p_{n}$ and $b, \gamma>0$.

Assumption 2.5. The quantity of the raw materials of recycled waste products $\Omega$ is a linear function of the recovery price of the retailer $\eta_{r}$, that is $\Omega\left(\eta_{r}\right)=g+k \eta_{r}$, and $g \geq 0, k \geq 0 . k$ is the sensitivity coefficient of recovery price; is the quantity of waste products submitted by consumers. $g$ reflects the degree of consumers' awareness of environmental protection.

Assumption 2.6. As in [13], the social welfare function of the government mainly includes: "chain-based producer surplus $(P S)$ and the economic influence (EI) measures". A ps is the profit brought by the difference between the supply price and the current market price. The is defined as the budget surplus after the government takes financial incentive measures to the players of the supply chain. Therefore, similar to the research of [13,16], $P S=\pi_{m}+\pi_{r}, E I=(1+\delta) T . \delta$ is the fixed cost input coefficient of the government, thus $S W=P S+E I$. 


\subsection{The government incentive regulation model}

\section{The profit of the retailer}

Because the new and remanufactured products are priced differently in the CLSC, the retailer sells the new products to consumers at the price of $p_{n}$ and sells the remanufactured products at the price $p_{r}$ of The unit cost of sales for the retailer in forward logistics is $c_{a}$ and the recovery cost in the reverse logistics is $c$. In addition, the recovery price of the manufacturer from the retailer is $\eta_{m}$, and the recovery price of the retailer from consumers is $\eta_{r}$. To improve the recovery efficiency, the government gives a transfer payment of $T$ to the retailer and the retailer makes an effort of $e$ and suffers certain costs. Therefore, the profit function of the retailer is shown as follows:

$$
\pi_{r}(\beta)=D_{n}\left(p_{n}-w_{n}-c_{a}\right)+D_{r}\left(p_{r}-w_{r}-c_{a}\right)+\Omega(\beta)\left(\eta_{m}(\beta)-\eta_{r}(\beta)-c(\beta)\right)-\phi(e)+T(\beta)
$$

where $\omega$ is the quantity of recycled waste products and $\varphi_{(e)}$ is the effort costs.

\section{The profit of the manufacturer}

The manufacturer produces products with new and recycled materials, the unit production cost of the new products is $c_{n}$ and the remanufactured products is $c_{r}$. The wholesale price of new products set by the manufacturer is $w_{n}$ and the remanufactured products is $w_{r}$. Thus the profit function of the manufacturer is shown as follows:

$$
\pi_{m}(\beta)=D_{n}\left(w_{n}-c_{n}\right)+D_{r}\left(w_{r}-c_{r}\right)+v\left(\Omega(\beta)-D_{r}\right)+\Omega(\beta)\left(c_{n}-c_{r}-\eta_{m}(\beta)\right) .
$$

\section{The target of government}

The government's goal is to maximize social welfare. The social welfare function mainly includes chain-based producer surplus and the government's budget surplus after taking the retailer's incentives measures. Therefore, the total social welfare from different retailers with different recovery costs is shown as follows:

$$
S W=\int_{\underline{\beta}}^{\bar{\beta}}(P S+E I) \mathrm{d} F(\beta) .
$$

\section{The incentive constraints of the government to the retailer}

The government signs a contract with the retailer based on the reported recovery cost $\hat{\beta}$ and reimburses the retailer according to the contract selected by the retailer, which may not reveal the true recovery cost of the retailer. Therefore, the profit function of the retailer is composed of the true recovery cost $\beta$ and the reported recovery cost $\hat{\beta}$ and is shown as follows

$$
\pi_{r}(\beta, \hat{\beta})=D_{n}\left(p_{n}-w_{n}-c_{a}\right)+D_{r}\left(p_{r}-w_{r}-c_{a}\right)+\Omega(\hat{\beta})\left(\eta_{m}(\hat{\beta})-\eta_{r}(\hat{\beta})-c(\hat{\beta})\right)-\phi(\beta-c(\hat{\beta}))+T(\hat{\beta}) .
$$

Therefore, when each $\beta_{1}, \beta_{2} \in(\underline{\beta}, \bar{\beta})$, where $\beta_{1}, \beta_{2}$ indicates different types of recovery costs for the retailer, we can obtain the incentive constraints from the government to the retailer as follows:

$$
\begin{aligned}
& D_{n}\left(p_{n}-w_{n}-c_{a}\right)+D_{r}\left(p_{r}-w_{r}-c_{a}\right)+\Omega\left(\beta_{1}\right)\left(\eta_{m}\left(\beta_{1}\right)-\eta_{r}\left(\beta_{1}\right)-c\left(\beta_{1}\right)\right)-\phi\left(\beta_{1}-c\left(\beta_{1}\right)\right)+T\left(\beta_{1}\right) \geq \\
& D_{n}\left(p_{n}-w_{n}-c_{a}\right)+D_{r}\left(p_{r}-w_{r}-c_{a}\right)+\Omega\left(\beta_{2}\right)\left(\eta_{m}\left(\beta_{2}\right)-\eta_{r}\left(\beta_{2}\right)-c\left(\beta_{2}\right)\right)-\phi\left(\beta_{1}-c\left(\beta_{2}\right)\right)+T\left(\beta_{2}\right) \\
& D_{n}\left(p_{n}-w_{n}-c_{a}\right)+D_{r}\left(p_{r}-w_{r}-c_{a}\right)+\Omega\left(\beta_{2}\right)\left(\eta_{m}\left(\beta_{2}\right)-\eta_{r}\left(\beta_{2}\right)-c\left(\beta_{2}\right)\right)-\phi\left(\beta_{2}-c\left(\beta_{2}\right)\right)+T\left(\beta_{2}\right) \geq \\
& D_{n}\left(p_{n}-w_{n}-c_{a}\right)+D_{r}\left(p_{r}-w_{r}-c_{a}\right)+\Omega\left(\beta_{1}\right)\left(\eta_{m}\left(\beta_{1}\right)-\eta_{r}\left(\beta_{1}\right)-c\left(\beta_{1}\right)\right)-\phi\left(\beta_{2}-c\left(\beta_{1}\right)\right)+T\left(\beta_{1}\right) .
\end{aligned}
$$

Equations (2.5) and (2.6) show that in order to induce the retailer to make the optimal effort, the contract designed by the government should also meet the incentive compatibility constraints of the retailer. This mechanism means that if the retailer chooses the contract that does not match its true type, the retailer will get an 
optimal profit, and this profit will be lower than the expected profit when he intends to choose the recycled cost type, so that different types of retailer can not imitate each other.

\section{The participants constraint of the retailer}

To enable the retailer to develop the recycling activities normally and to participate in this regulation actively, the government should make the profit of the retailer no less than when the retailer is out of this regulation. Thus the constraint is shown as follows:

$$
\pi_{r}(\beta, \hat{\beta}) \geq 0
$$

To sum up the analysis, the problem can be described as follows:

$$
S W=\max _{T(\cdot)} \int_{\underline{\beta}}^{\bar{\beta}}(P S+E I) d F \beta \quad \text { s.t.(5), (6), (7). }
$$

Combining the equations (2.5) and (2.6), we can obtain

$$
\int_{\beta_{1}}^{\beta_{2}} \int_{c\left(\beta_{1}\right)}^{c\left(\beta_{2}\right)} \varphi^{\prime \prime}(x-y) d x d y \geq 0 .
$$

Because $\phi^{\prime \prime}(\cdot) \geq 0$, equation (9), we infers that $c^{\bullet}(\beta)$ is an increasing function on $\beta$, and $c(\beta) \geq 0$, or equivalently

$$
\varepsilon^{\prime}(\tau) \geq-1
$$

The recycler with low recovery rate may falsely report the information of recovery rate in order to obtain more profit, therefore, by applying the envelope theorem in the equation (2.4), we can get:

$$
e^{\bullet}(\beta) \leq 1
$$

In addition, when the retailer obtains more profit, the transfer payment of the government will increase. To save cost, the government orders $\pi_{r}(\bar{\beta})=0$, therefore, we can get the $\pi_{r}(\beta)$ from the equation (2.11)

$$
\pi_{r}(\beta)=\int_{\beta}^{\bar{\beta}} \phi^{\prime}(e(\tilde{\beta})) \mathrm{d} \tilde{\beta} .
$$

Proposition 2.7. When the recovery cost is low, the retailer's profit surplus is equivalent to equation (2.12), which we call the information rent.

Proposition 1 shows that under the government incentive regulation, the retailer's profit is related to the effort. In real life, when the government encourages the retailer to make an effort to reduce the recovery cost, it would generate certain effort costs, which will cause the investment to increase. Therefore, it is reasonable for the retailer to keep the surplus of the profit.

Corollory 2.8. Equation (2.11) shows that the retailer's redundant profit changes with the recovery cost in the opposite direction. That is the higher the recovery cost, the lower profit the retailer obtains. The incentive regulation mechanism of the government can effectively promote the retailer to reduce the recovery cost for more redundant profit.

Therefore, the total information rent of the retailer with different recovery costs is

$$
\begin{aligned}
\int_{\underline{\beta}}^{\bar{\beta}} \pi_{r}(\beta) d F(\beta) & =\int_{\underline{\beta}}^{\bar{\beta}} \int_{\beta}^{\bar{\beta}} \phi^{\prime}(e(\tilde{\beta})) \mathrm{d} \tilde{\beta} d F(\beta) \\
& =\int_{\underline{\beta}}^{\bar{\beta}} \frac{F(\beta)}{f(\beta)} \phi^{\prime}(e(\beta)) d F(\beta) .
\end{aligned}
$$


Substituting equations (2.2), (2.4), and (2.13) into equation (2.8), we can get the problem of the government as follows

$$
\begin{aligned}
& S W=\max _{T(\bullet)} \int_{\underline{\beta}}^{\bar{\beta}}\left[-\delta \frac{F(\beta)}{f(\beta)}-(1+\delta) \phi(e)+D_{n}\left(w_{n}-c_{n}\right)+D_{r}\left(w_{r}-c_{r}\right)+v\left(\Omega-D_{r}\right)+\Omega(\beta)\left(c_{n}-c_{r}+\right.\right. \\
& \left.\left.\quad \eta_{m}(\beta)\right)+(1+\delta)\left(D_{n}\left(p_{n}-w_{n}-c_{a}\right)+D_{r}\left(p_{r}-w_{r}-c_{a}\right)+\Omega(\beta)\left(\eta_{m}(\beta)-\eta_{r}(\beta)-c(\beta)\right)\right)\right] \mathrm{d} F(\beta) \\
& \quad \text { s.t.(10). }
\end{aligned}
$$

In a market dominated by the manufacturer under the government incentive regulation, the relationship among the government, the manufacturer, and the retailer can be constructed as a three-stage Stackelberg game model. In the first stage, under the regulation goal of maximizing social welfare, the government formulates an incentive regulation mechanism for the retailer to expose the true recovery cost and guide the retailer to make a reasonable effort. In the second stage, the manufacturer makes the wholesale price and the recovery price strategies. Based on the government's strategies and manufacturer in the previous steps, the retailer makes the optimal retail price and the recovery price strategies in the third stage. The backward induction is applied to solve this problem.

In the third stage, the retailer determines the optimal recovery price and retail price strategies. When the report recovery cost by the retailer is $\hat{\beta}$, the profit function of the retailer is

$$
\pi_{r}(\hat{\beta})=D_{\mathrm{n}}\left(p_{n}-w_{n}-c_{a}\right)+D_{\mathrm{r}}\left(p_{r}-w_{r}-c_{a}\right)+\Omega(\hat{\beta})\left(\eta_{m}(\hat{\beta})-\eta_{r}(\hat{\beta})-c(\hat{\beta})\right)-\phi(e(\hat{\beta}))+T(\hat{\beta}) .
$$

For the $\pi_{r}(\hat{\beta})$ in equation (2.15), the first derivatives of $p_{n}, p_{r}$ and $\eta_{r}$ are obtained and made it to be zero, the reaction formulas are obtained as follows:

$$
\begin{aligned}
p_{n} & =\frac{\alpha}{2(b-\gamma)}+\frac{w_{n}+c_{a}}{2} \\
p_{r} & =\frac{\alpha}{2(b-\gamma)}+\frac{w_{r}+c_{a}}{2} \\
\eta_{r}(\hat{\beta}) & =\frac{\eta_{m}-c(\hat{\beta})}{2}-\frac{g}{2 k} .
\end{aligned}
$$

In the second stage, the manufacturer decides the optimal recovery price and wholesale price strategies with the retailer's reported recovery cost $\hat{\beta}$.

By substituting equation (2.16) into equation (2.15), the first derivatives of $w_{n}, w_{r}$ and $\eta_{m}$ are obtained and made it to be zero,we can obtain:

$$
\begin{aligned}
w_{n} & =\frac{\alpha+(b-\gamma)\left(c_{n}-c_{a}\right)}{2(b-\gamma)} \\
w_{r} & =\frac{\alpha+(b-\gamma)\left(v+\theta c_{n}-c_{a}\right)}{2(b-\gamma)} \\
\eta_{m}(\hat{\beta}) & =\frac{k\left(v+c_{n}-c_{r}+c(\hat{\beta})\right)}{2 k} .
\end{aligned}
$$

Then, equation (2.17) can be substituted into equation (2.16) to obtain the retailer's optimal pricing strategies under the leadership of the manufacturer.

$$
\begin{aligned}
p_{n} & =\frac{3 \alpha+(b-\gamma)\left(c_{n}+c_{a}\right)}{4(b-\gamma)} \\
p_{r} & =\frac{3 \alpha+(b-\gamma)\left(v+\theta c_{n}+c_{a}\right)}{4(b-\gamma)} \\
\eta_{r}(\beta) & =\frac{k\left(v+c_{n}-c_{r}-c(\beta)\right)}{4 k} .
\end{aligned}
$$


In the first stage, the government gives a transfer payment to the retailer to encourage the retailer to improve the recovery efficiency and make an optimal effort. In order to obtain the optimal allocation of the social resources, the government provides a contract equal to the total expected costs of the retailer to absorb the expected rent fully.

Because $\phi^{\prime \prime \prime}(e)=0$, ignoring the constraint of equation (2.10) temporarily and calculating the first derivative of $e(\beta)$ from equation (2.14),we get

$$
\varphi^{\prime}(e(\beta))=\frac{-\delta}{1+\delta} \frac{F(\beta)}{f(\beta)} \varphi^{\prime \prime}(e(\beta))+\frac{k v+k c_{n}+k \eta_{m}(\beta)-2 k \eta_{r}(\beta)-2 g-k c_{r}}{4(1+\delta)}+\frac{g+k \eta_{m}(\beta)-k c(\beta)}{4} .
$$

Proposition 2.9. The optimal effort level for the retailer with the government incentive regulation is decided by equation (2.19). Equation (2.19) describes a one-to-one correspondence between the recovery cost $\beta$ and the optimal effort $e$. The retailer with different types of recovery costs will make a different efforts.

Corollory 2.10. The retailer's optimal effort level has the opposite trend with the recovery cost of the waste products.

we can also get the first derivative of from equation (2.19):

$$
\dot{e}(\beta)=\frac{-\delta /(1+\delta) \mathrm{d} / \mathrm{d} \beta(F(\beta) / f(\beta))+(3 k+\delta k) / 8 \varphi^{\prime \prime}(e(\beta))(1+\delta)}{1+(3 k+\delta k) / 8 \varphi^{\prime \prime}(e(\beta))(1+\delta)} .
$$

From equation (2.20), it is obvious that which meets the constraint in equation (2.10).

Consequently, we can get the optimal effort $e^{*}(\beta)$ made by the retailer from equation (2.20). Therefore, the recovery cost of the retailer is also obtained:

$$
c^{*}(\beta)=\beta-e^{*}(\beta) .
$$

Substituting equation (2.21) into equation (2.17), we can obtain the optimal pricing strategies, and the profit of the manufacturer

$$
\begin{aligned}
w_{n}^{*} & =\frac{\alpha+(b-\gamma)\left(c_{n}-c_{a}\right)}{2(b-\gamma)} \\
w_{r}^{*} & =\frac{\alpha+(b-\gamma)\left(v+\theta c_{n}-c_{a}\right)}{2(b-\gamma)} \\
\eta_{m}^{*}(\beta) & =\frac{k\left(v+c_{n}-c_{r}+c^{*}(\beta)\right)}{2 k} \\
\pi_{m}^{*}(\beta) & =\frac{g^{2}-k^{2}\left(c^{*}(\beta)-v-c_{r}+c_{n}\right)\left(v+c_{r}-c_{n}-c^{*}(\beta)\right)}{8 k} \\
& +\frac{\alpha^{2}-\alpha\left(2 c_{a}+c_{n}+\theta c_{n}+v\right)(\beta-\gamma)}{4(\beta-\gamma)}+\frac{g\left(v-c^{*}(\beta)\right)}{4} \\
& +\frac{g\left(c_{r}-c_{n}\right)-\gamma\left(c_{n}+c_{a}\right)\left(c_{n}+\theta c_{a}+v\right)}{4}+\frac{\left[\left(c_{n}+c_{a}\right)^{2}+\left(c_{r}+c_{a}\right)^{2}+2 v\left(c_{r}+c_{a}+v\right)\right] \beta}{8} .
\end{aligned}
$$

Proposition 2.11. The profit of the manufacturer decreases with the increase of the retailer's operating costs.

From equation (2.22), we can see that $\frac{\partial \pi_{m}^{*}(\beta)}{\partial c_{a}}=\frac{c_{n}\left(\left(c_{a}+v\right) \beta-\left(c_{a}+\theta c_{n}+c_{n}\right) \gamma-\alpha\right)}{4}<0$, similarly, $\frac{\partial \pi_{m}^{*}(\beta)}{\partial c^{*}(\beta)}<0$. It shows that the manufacturer's profit function is decreasing with the retailer's operating cost. The higher the retailer's operating cost, the lower the profit. $c_{a}$ and $c$ represent the retailer's forward and reverse operation costs respectively, which reflect the level of the retailer's operation management. The smaller the $c_{a}$ and $c$, the higher level of the retailer's operation management. That is the lower of the retailer's cost not only brings 
more profit to the retailer, but also improves the manufacturer's profit, and makes the economic benefits for the CLSC system more significant. Both sides of the game can achieve a win-win situation.

Substituting equation (2.20) into equation (2.18), we obtain the optimal pricing strategies of the retailer

$$
\begin{aligned}
p_{n}^{*} & =\frac{3 \alpha+(b-\gamma)\left(c_{n}+c_{a}\right)}{4(b-\gamma)} \\
p_{r}^{*} & =\frac{3 \alpha+(b-\gamma)\left(v+\theta c_{n}+c_{a}\right)}{4(b-\gamma)} \\
\eta_{r}^{*}(\beta) & =\frac{k\left(v+c_{n}-c_{r}-c^{*}(\beta)\right)}{4 k} .
\end{aligned}
$$

Proposition 2.12. $w_{n}^{*}, w_{r}^{*}, \eta_{m}^{*}(\beta), \eta_{r}^{*}(\beta), p_{n}^{*}, p_{r}^{*}$ are the optimal decisions of the manufacturer and retailer respectively.

Proposition 2.13. The optimal wholesale price and retail price are increasing functions for the cost-saving rate of remanufacturing $\theta$.

From $\frac{\partial w_{r}^{*}}{\partial \theta}=2\left(\frac{\partial p_{r}^{*}}{\partial \theta}\right)=\frac{c_{n}}{2}>0$, we can see that with the increase of $\theta$, the wholesale price and retail price also increase. $\theta$ refers to the cost rate saved by the manufacturer in remanufacturing, which reflects the level of the social remanufacturing technology. A higher value $\theta$ indicates a lower remanufacturing technology level of the manufacturer, and small cost reduction;this leads to a higher product price born by the consumers. Therefore, the cost saving rate of remanufacturing $\theta$ can also affect the optimal decision-making of the retailer.

Finally, the optimal profit of retailer $\pi_{r}^{*}(\beta)$ and the transfer payment of government $T^{*}(\beta)$ are

$$
\begin{gathered}
\pi_{r}^{*}(\beta)=\int_{\beta}^{\bar{\beta}} \phi^{\prime}\left(e^{*}(\tilde{\beta})\right) \mathrm{d} \tilde{\beta} \\
T^{*}(\beta)=\pi_{r}^{*}(\beta)+\phi\left(e^{*}(\beta)\right)-D_{n}\left(p_{n}-w_{n}-c_{a}\right)-D_{r}\left(p_{r}-w_{r}-c_{a}\right)-\Omega^{*}(\beta)\left(\eta_{m}^{*}(\beta)-\eta_{r}^{*}(\beta)-c^{*}(\beta)\right) .
\end{gathered}
$$

Proposition 2.14. In order to monitor the waste products recovery cost of the retailer with the effort $c^{*}(\beta)$, the government obtains the original recovery cost of the retailer from, where the solution is given in equation (2.19).

Proposition 2.15. The retailer's profit is closely related to the effort level and with the decrease of the retailer's recovery cost $\beta$, the profit increase.

From equations (2.10) and (2.24), we know that the retailer can increase the recovery effort to get more profit. However, the recovery effort input is always accompanied by a higher cost. At this time, the government regulates the retailer to guide them to make a reasonable investment, improving the level of recovery efficiency and achieving the maximized profit.

Proposition 2.16. Under the government inventive regulation and with the social welfare maximization as the regulation target, there is an optimal level on the transfer payment for the government

$$
T^{*}(\beta)=\pi_{r}^{*}(\beta)+\phi\left(e^{*}(\beta)\right)-D_{n}\left(p_{n}-w_{n}-c_{a}\right)-D_{r}\left(p_{r}-w_{r}-c_{a}\right)-\Omega\left(\eta_{m}^{*}(\beta)-\eta_{r}^{*}(\beta)-c^{*}(\beta)\right)
$$

Under the government regulation, when the government observes the reverse recovery cost of the retailer with the effort $c^{*}(\beta)$, there is the best point in transferring payment lines to the retailer. From $\partial S W^{*}\left(\beta / \partial T^{*}(\beta)=\right.$ $-(1+\delta)<0$, it can be seen that social welfare is a concave function on the transfer payment of the government. When the transfer payment of the government is lower than the optimal level, the social welfare increases with the improvement of incentive strength. However, when it is higher than the optimal level, the social welfare decreases with the improvement of incentive strength. 
Proposition 2.17. When the effort costs of the retailer improve, the intensity of government incentive increases.

From equation $(2.25), \partial T^{*}(\beta) / \partial \phi\left(e^{*}(\beta)\right)=\phi\left(e^{*}(\beta)\right)>0$. we know that When the retailer improves the effort to improve the level of recycling efficiency, they need the support from government to alleviate the investment pressures. Thus, with the increase of the incentive intensity, the retailer can effectively innovate in recycling technology.

Proposition 2.18. With the improvement of the market capacity, the intensity of government incentive decreases.

From equation $(2.25), \partial T^{*}(\beta) / \partial \alpha=(-7) / 4(b-\gamma)<0$. The larger the market capacity, the lower the incentive strength. Therefore, when implementing the inventive mechanism, the government should consider the products' market capacity to formulate a reasonable transfer payment rather than adopting the "one size fits all" approach for all players.

Proposition 2.19. The information asymmetry reduces the intensity of the incentive programs (less effort).

The government incentive mechanism is conducive to promoting the retailer to increase the effort to reduce the recovery cost. However, when both sides of the game players are in the state of information asymmetry, it will be more difficult for the government to control the recycling activities of the retailer, thus it cannot improve the social welfare and effectively promote the retailer to make the optimal effort.

$c^{*}(\beta)$ can be replaced by its inverse function $\beta=\beta^{*}(c)$. Thus, the optimal transfer payment by the government

$$
\begin{aligned}
T^{*}(c)= & \int_{\beta}^{\bar{\beta}} \phi^{\prime}\left(e^{*}(\tilde{\beta}(c))\right) \mathrm{d} \tilde{\beta}+\phi\left(e^{*}(\beta(c))\right)-D_{n}\left(p_{n}-w_{n}-c_{a}\right)-D_{r}\left(p_{r}-w_{r}-c_{a}\right)+e(\beta(c)) \\
& -\Omega^{*}(\beta(c))\left(\eta_{m}^{*}(\beta(c))-\eta_{r}^{*}(\beta(c))-\beta(c)\right) .
\end{aligned}
$$

Proposition 2.20. When the $\partial^{\prime \prime \prime} \phi / \partial^{\prime \prime} e \partial \omega \geq 0$, the increase of the intensity of alternative activities reduces the intensity of the optimal incentive scheme: $\partial e^{*}(\beta) / \partial \omega<0$.

When the alternative activities (such as investment or quality improvement) are used in other ways: $c=$ $(\beta-e)+\omega$ increases the cost and the negative effect of effort is $\phi(\bullet)$, there is $\partial \phi / \partial \omega>0, \partial^{2} \phi / \partial$ e $\partial \omega>$ $0, \partial^{3} \phi / \partial^{2} \mathrm{e} \partial \omega \geq 0$. Replaced with $e=\beta-c+\omega$, The negative effect of effort is Then the above assumption becomes The conclusion is in the sense of the effort of crowding out alternative activitiesin other words, lowintensity incentive schemes are needed to encourage alternative activities.

In summary, by building its incentive regulation game model, the government can obtain the original recovery efficiency by regulating the retailer's recovery cost with effort. Under the government's incentive regulation to maximize social welfare, the retailer will make an optimal effort. Correspondingly, the government would give the retailer a transfer payment to promote recycling efficiency. The optimal pricing decisions of the manufacturer and the retailer are also calculated. Finally, the government incentive regulation can effectively reduce the impact of information asymmetric on the management of CLSC.

\subsection{Government closes down the inefficient companies}

Due to the hysteresis of market regulation, the inefficient recycling company occupies the market resources, which will lead to a long-term process of maximizing social welfare. In order to improve the efficiency of social resource allocation and maximize social welfare, it is necessary for the government to intervene in the recycling activities of company. This section studies the government closes down inefficient recycling company. Starting from the overall social welfare, we consider the possibility that the recycling activities of the retailer would not be achieved for all types. Assuming $\beta^{*}$ is the "critical" production type, the type retailer produced in $\left(\underline{\beta}, \beta^{*}\right)$ 
and do not produce in $\left(\beta^{*}, \bar{\beta}\right) . U\left(\beta, \beta^{*}\right)$ is the profit of the type retailer when the critical type of production is $\beta^{*}$. Therefore, we can obtain the function of the social welfare as follows.

$$
\begin{aligned}
S W\left(\beta^{*}, e(\beta)\right) & =\int_{\underline{\beta}}^{\bar{\beta}}-\delta \pi_{r}\left(\beta, \beta^{*}\right)-(1+\delta) \phi\left(e^{*}(\beta)\right)+D_{n}\left(w_{n}-c_{n}\right)+D_{r}\left(w_{r}-c_{r}\right)+v\left(\Omega-D_{r}\right) \\
& +\Omega\left(c_{n}-c_{r}+\eta_{m}^{*}(\beta)\right)+(1+\delta)\left(D_{n}\left(p_{n}-w_{n}-c_{a}\right)+D_{r}\left(p_{r}-w_{r}-c_{a}\right)\right. \\
& \left.+\Omega\left(\eta_{m}^{*}(\beta)-\eta_{r}^{*}(\beta)-c^{*}(\beta)\right)\right) d F(\beta) .
\end{aligned}
$$

The above formula means that for all $\beta \leq \beta^{*}$,

$$
\pi_{r}\left(\beta, \beta^{*}\right)=\int_{\beta}^{\beta^{*}} \varphi^{\prime}\left(e^{*}(\tilde{\beta})\right) \mathrm{d} \tilde{\beta} .
$$

Substituting equation (2.28) into equation (2.27) and formulating the derivative about $\beta^{*}$ for the expected social welfare.we obtain

$$
\begin{aligned}
& f\left(\beta^{*}\right)\left(-(1+\delta) \phi\left(e^{*}\left(\beta^{*}\right)\right)+D_{n}\left(w_{n}-c_{n}\right)+D_{r}\left(w_{r}-c_{r}\right)+v\left(\Omega-D_{r}\right)+\Omega\left(c_{n}-c_{r}\right.\right. \\
& \left.+\eta_{m}^{*}\left(\beta^{*}\right)\right)+(1+\delta)\left(D_{n}\left(p_{n}-w_{n}-c_{a}\right)+D_{r}\left(p_{r}-w_{r}-c_{a}\right)+\Omega\left(\eta_{m}^{*}\left(\beta^{*}\right)-\eta_{r}^{*}\left(\beta^{*}\right)-c^{*}\left(\beta^{*}\right)\right)\right) \\
= & \delta F\left(\beta^{*}\right) \phi^{\prime}\left(e^{*}\left(\beta^{*}\right)\right) .
\end{aligned}
$$

To explain how $\beta^{*}$ depends on the effort level $e$, let $\beta^{*}$ indicates the optimal recycling efficiency of the retailer with the effort level $e_{0}$ and $\beta_{1}^{*}$ indicate the optimal recycling efficiency of the retailer with the effort level $e_{1}$. The Display preference theory shows that $S W\left(\beta_{0}^{*}, e_{0}\right) \leq S W\left(\beta_{1}^{*}, e_{0}\right)$ and Adding up these two inequalities we get

$$
\int_{\beta_{0}^{*}}^{\beta_{1}^{*}} \int_{e_{0}}^{e_{1}} \frac{\partial^{2} S W}{\partial e} d e d \beta^{*} \leq 0
$$

and the derivation of the retailer's effort $e$ in $\frac{\partial S W}{\partial \beta^{*}}$ is formulated as follows

$$
\frac{\partial^{2} S W}{\partial e \partial \beta^{*}}=f\left(\beta^{*}\right)\left(-(1+\delta) \phi^{\prime}\left(e\left(\beta^{*}\right)\right)-\delta F\left(\beta^{*}\right) \phi^{\prime \prime}\left(e\left(\beta^{*}\right)\right)\right) e^{\prime}\left(\beta^{*}\right)<0 .
$$

Therefore, we can conclude that $e_{1}>e_{0} \Rightarrow \beta_{1}^{*} \leq \beta_{0}^{*}$.

Proposition 2.21. If the effort level is sufficiently high,for all types $\left(\beta^{*}=\bar{\beta}\right)$, the recycling activities of the retailer can be carried out normally.

When the retailer's effort is high enough to improve the level of recycling technology, the government will allow the recycling activities to go on. Therefore, for the retailer, if the retailer wishes to get more profit in multiple ways and survive in the market competition, the retailer should increase the innovation of recycling technology and reduce the cost of recovery.

\section{EXAMPLE ANALYSis}

\subsection{Numerical example analysis}

In this part, we provide a specific numerical example to explain and verify the above results. The numerical settings follow the model assumptions and conform to the reasonable relationship between the parameters. Assuming that the related parameters are shown in Table 3, the cost for the retailer to make an effort is $\phi=\left(\sigma e^{2}\right) / 2$. The recovery cost of retailer $\beta$ follows the uniformly distributed on [0.1.0.4], the cumulative distribution function $F(\beta)=(10 \beta-1) / 3$ and the density function $f(\beta)=(10 / 3)$. The government can regulate the retailer based on $\beta$ or $c$ Therefore, substi- tuting the numerical values into the model, the original recovery 
TABLE 3. The values of related parameters in CLSC.

\begin{tabular}{cccccccccccccc}
\hline \hline Parameters & $\beta$ & $c_{n}$ & $c_{r}$ & $c_{a}$ & $\alpha$ & $b$ & $\gamma$ & $g$ & $v$ & $k$ & $\theta$ & $\delta$ & $\sigma$ \\
\hline Values & {$[0.1 .0 .4]$} & 20 & 10 & 2 & 500 & 20 & 10 & 10 & 10 & 0.7 & 0.1 & 0.2 & $10^{6}$ \\
\hline
\end{tabular}

TABLE 4. Equilibrium values of the variables.

\begin{tabular}{ccc}
\hline \hline & $\beta$ & $c$ \\
\hline$\beta$ & $\beta$ & $0.9229 c+0.0139$ \\
$e^{*}$ & $0.0151-0.0836 \beta$ & $-0.0771 c+0.0139$ \\
$c^{*}$ & $1.0836 \beta-0.0151$ & $c$ \\
$\eta_{m}^{*}$ & $9.9925+0.4582 \beta$ & $10+0.5 c$ \\
$\eta_{r}^{*}$ & $10.0076-0.4582 \beta$ & $10-0.5 c$ \\
$T^{*}$ & $-1117.2+2524.72 \beta+6988.96 \beta^{2}$ & $-1203.875+1504.8 c+4158.72 c^{2}$ \\
\hline
\end{tabular}

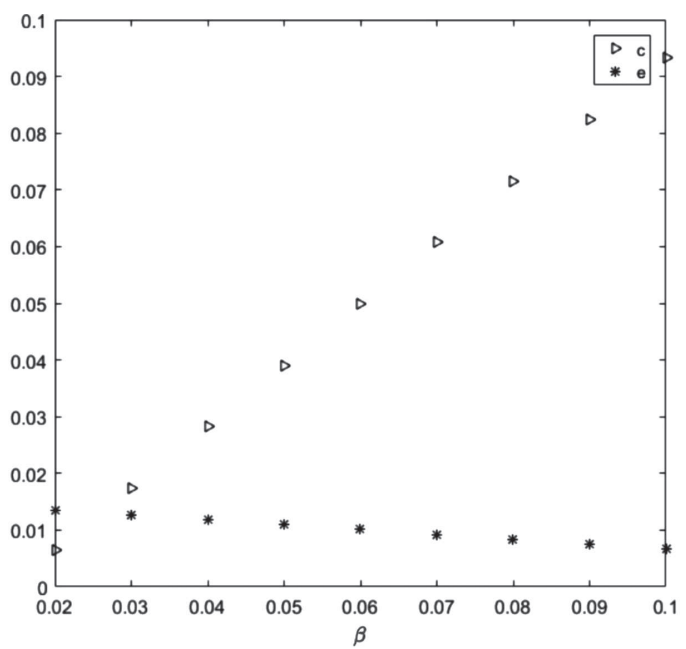

Figure 3. The effect of $\beta$ on $c$ and e.

cost of the retailer, the optimal effort made by the retailer, the unit recovery cost of retailer in the reverse logistics regulated by the government, the recovery price of the manufacturer from the retailer, the recovery price of the retailer from consumers and government transfer payment to the retailer are obtained and as shown in Table 4.

\subsection{Basic variable sensitivity analysis}

To investigate the changes of parameters in the government incentive regulation model, we conduct the sensitivity analysis on the coefficients of $\beta, g$ and $k$, which can provide more methods and suggestions for the government and CLSC players in practice.

The impacts of change in the coefficient $\beta$ on recovery cost of the retailer regulated by government $c$ the effort made by the retailer $e$, the transfer payment of government to retailer $T$. the profit of manufacturer $\pi_{m}$ the recovery prices of manufacturer $\eta_{m}$ and retailer $\eta_{r}$ are shown in Figures 3-7. From Figures 3-7, we can conclude 


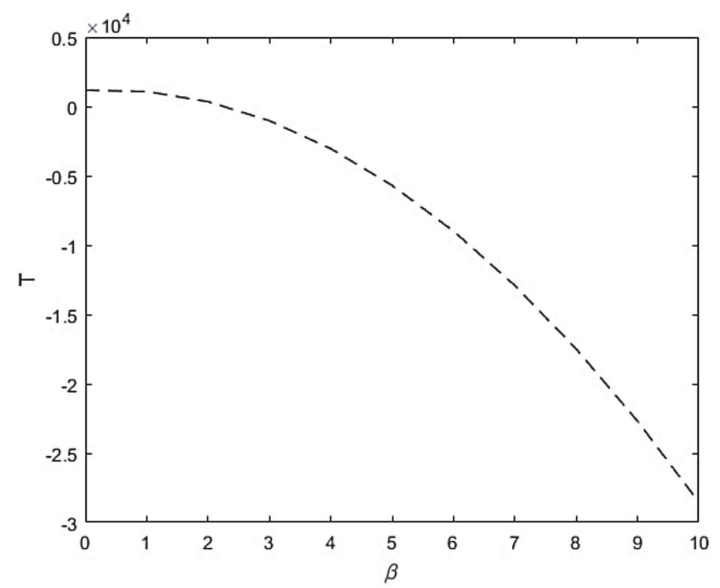

FiguRE 4 . The effect of $\beta$ on the transfer payment $T$.

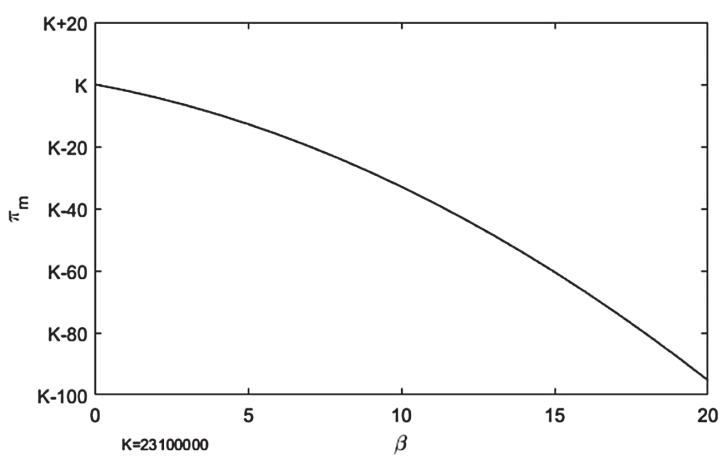

FiguRE 5. The effect of $\beta$ on profit of the manufacturer $\pi_{m}$.

(i) According to Figure 3, as the original recovery $\operatorname{cost} \beta$ decreases, the retailer improves the effort $e$, thus the recovery cost of retailer with effort reduces. It shows that under the government incentive regulation, the retailer can improve the recovery efficiency by increasing the effort.

(ii) Figure 4 indicates that when the original recovery cost of retailer increases, the transfer payment of government decreases. By raising the incentive intensity, the government can promote the retailer to improve the recovery efficiency. Correspondingly, the effort made by the retailer will also increase, so as to maximize the profit.

(iii) Figure 5 indicates that the profit of the manufacturer is also affected by the true recovery cost of the retailer The profit of the manufacturer increases when the original recovery cost of the retailer decreases.Therefore, when the retailer improves the recovery technology level, the profit of the manufacturer also increase and bring more economic benefits for the CLSC system, that is both sides of the game could achieve a win-win situation.

(iv) From Figures $6-7$, we can see that as the original reverse operating cost type of the retailer $\beta$ increases, the recovery price of the manufacturer from retailer also increases. However, the recovery price of retailer from consumers decreases. When the retailer's recycling technology level is low, the retailer's recycling cost is high, however, the $R \& D$ investment in recycling the waste products of the retailer is smaller, thus the recycling price of the manufacturer decreases; however, when the retailer's recycling technology level is higher, the retailer's 


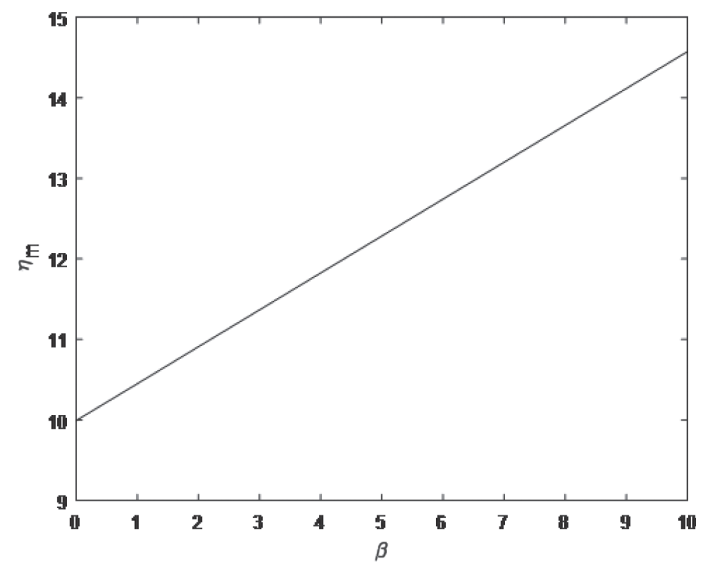

FiguRE 6 . The effect of $\beta$ on the recovery price of the manufacturer $\eta_{m}$.

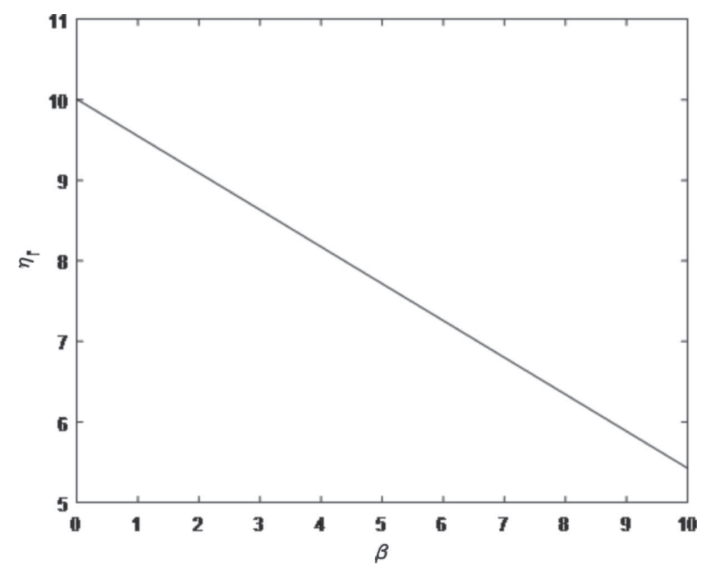

FiguRE 7 . The effect of $\beta$ on the recovery price of the retailer $\eta_{r}$.

recycling cost is smaller, and the $\mathrm{R} \& \mathrm{D}$ investment in recycling the waste products is larger, in order to ensure the retailer's normal profit, therefore, the recovery price of the manufacturer increases.

The attitude of consumers towards the environment protection can also affect the recovery efficiency. The quantity of waste products submitted by consumers and the sensitivity of consumers to the recycling price can also affect the level of social welfare. The impacts of change in the coefficients and on the social welfare are described in Figures 8-10. Figure 10 describes the impact of $k$ on the social welfare more intuitively.

(v) In Figure 8, the effect of $\beta$ on the social welfare $S W$ is described. As the number of waste products submitted by consumers increases, social welfare improves, consumers' awareness of environmental protection is closely related to social welfare. Under the regulation goal of maximizing social welfare, the government should strengthen the public's awareness of environmental protection and increase consumers' enthusiasm to recycling waste products. The stakeholders of companies and all the players of society should participate in recycling activities to improve social welfare.

(vi) In Figure 9, the more attention of consumers is paid to the recovery price, the higher the social welfare. Figure 10 describes the effect of $k$ on the social welfare $S W$ more intuitively. Con- sumers provide the waste products with the purpose of maximizing their own profit, thus when the consumers are more sensitive to the 


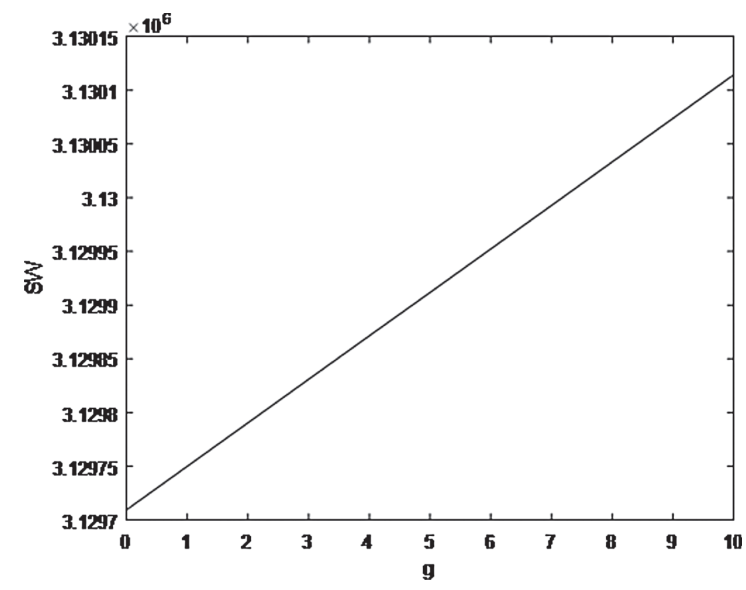

Figure 8. The effect of on the social welfare.

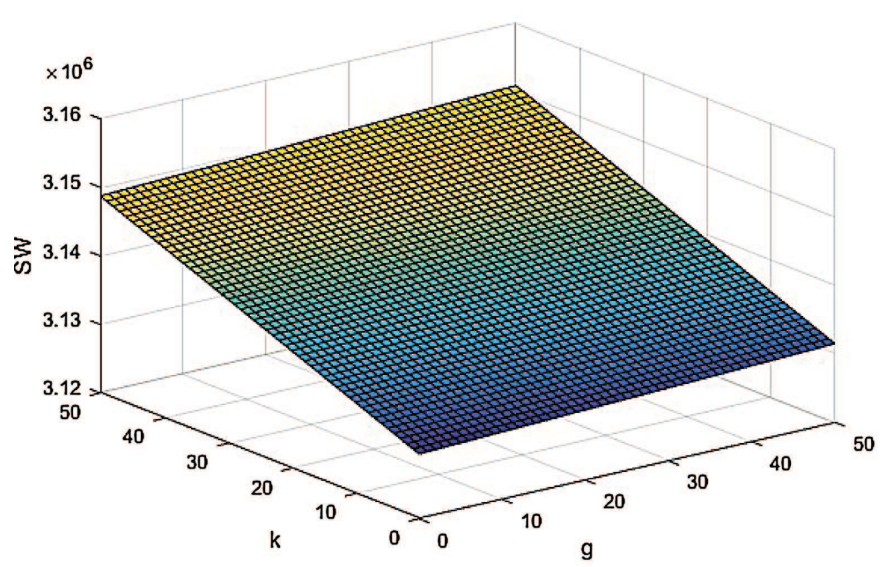

Figure 9. The effect of and on the social welfare.

recycling of waste products, they would increase the effort to get more profit, makes the recovery rate of the waste products in the whole society increase and promotes the social welfare.

In summary, to maximize social welfare, the government tends to pay more attention to the environmental protection and operation of the CLSC. Under the condition that the retailer reports the true recovery cost to the government, the retailer's profit will be optimal.

By analyzing the role of the recycler with different recycling cost in the market, this paper provides a solution for the sustainable management of CLSC under dual-information asymmetry, and provides a theoretical basis for the government to encourage the recycler to improve recycling efforts and achieve the sustainable development of the environment.

\section{Conclusions}

This study explored the CLSC comprising the manufacturer, retailer, and consumers. Based on the government incentive regulation theory, we considered the recovery cost and effort of retailers that the government cannot observe; alternatively, under asymmetric information, it investigated how the government designs an 


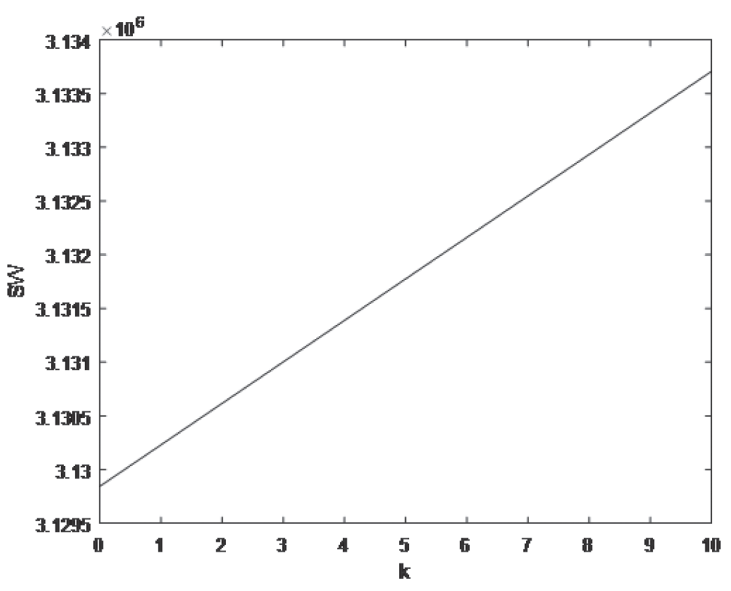

Figure 10. The effect of on the social welfare.

incentive mechanism to promote retailers to disclose the true recovery cost and enhance the recovery effort after signing the contract. Per the analysis provided above, the following conclusions are drawn: (i) the government could effectively solve the impact of asymmetric information on CLSC management by establishing the related incentive mechanism, which could encourage retailers to disclose the true recovery cost and make the optimal effort to decrease the recovery cost. (ii) To maximize social welfare, there is an optimal level for the government incentive intensity; when it is lower than the optimal level, social welfare increases as the incentive intensity increases. However, when it higher than the optimal level, social welfare decreases with an increase of incentive intensity. (iii) The government could regulate retailers using different ways such as the regulation based on $\beta$ and $c$. (iv) As retailers make an effort to improve the recycling level, the government could increase the incentive intensity; however, it could also increase the investment cost, which to some extents decrease the retailers' motivation. Thus, the government cannot blindly require retailers to make an effort;its focus should be more on controlling the investment cost. (v) With an increase in market capacity, the incentive intensity increases. Hence, the government should set the incentive intensity per market capacity of products rather than the unified intensity for all retailers.

The government can not only supervise retailers by observing their recycling efforts but should also guide them to make a reasonable investment by controlling their costs. For the supply chain companies, to attain the maximum profit, the collaboration between retailers and manufacturers should be strengthened. For the government, the formulation of reasonable regulatory policies is influenced by various factors; thus, the corresponding policies should be formulated per the specific situation.

Our government incentive regulation model can be introduced into the regulation problem analysis, and the regulation problem can be considered an optimal mechanism design problem. Under the premise of the information structure, constraints, and feasible tools of regulators and regulated companies, both sides' behavior and optimal trade-off can be examined, and numerous issues in regulation can be examined as endogenous as possible. Moreover, the method is broadly applicable and can be used effectively in the internal incentive problem, private procurement problem, and transfer pricing problem. For industries other than those holding a natural monopoly, it is easy to establish an effective incentive structure by altering the property right structure, which is easy to reform. However, the reform of the natural monopoly industry is challenging worldwide, warranting advanced incentive theory guidance. Hence, the motivation theory used in this study could effectively guide the reform of companies. However, owing to the model's complexity, it is may be hard to obtain an intuitive result.

This study examined the decision-making model of the CLSC under government incentive regulation and discussed how the government and supply chain players make optimal decisions when the adverse selection and moral hazard coexist. However, in real life, to enhance recovery efficiency, companies often accompany external 
investments, which could be monetary and contractual or nonmonetary and noncontractual. Thus, based on this model, future research will explore the influence of government incentive regulation on enterprise investments.

Data availability. All the data in this manuscript are from the references, and all the data are available.

The conflict of interest statement. I declare that I do not have any conflict of interest in the process of submission and have been approved by the author for publication.

Funding information. This study was funded by the National Social Science Fund of China (Grant No. 17BGL252).

\section{REFERENCES}

[1] D. Aksen, N. Aras and A.G. Karaarslan, Design and analysis of government subsidized collection systems for incentivedependent returns. Int. J. Prod. Econ. 119 (2009) 308-327.

[2] A. Atasu, L.N. Van Wassenhove and M. Sarvary, Efficient take-back legislation. Prod. Oper. Manag. 18 (2009) $243-258$.

[3] G. Bi, M. Jin, L. Ling and F. Yang, Environmental subsidy and the choice of green technology in the presence of green consumers. Ann. Oper. Res. 255 (2017) 1-22.

[4] P. Bogetoft and H.B. Olesen, Quality incentives and supply chains: Managing salmonella in pork production. Am. J. Agric. Econ. 86 (2004) 829-834.

[5] P. Calcott and M. Walls, Waste, recycling, and "Design for Environment": Roles for markets and policy instruments. Resour. Energy Econ. 27 (2005) 287-305.

[6] T.M. Choi, Optimal return service charging policy for a fashion mass customization program. Serv. Sci. 5 (2013) 56-68.

[7] T.M. Choi, Y. Li and L. Xu, Channel leadership, performance and coordination in closed loop supply chains. Int. J. Prod. Econ. 146 (2013) 371-380.

[8] A. Corum, Z. Vayvay and E. Bayraktar, The impact of remanufacturing on total inventory cost and order variance. J. Clean. Prod. 85 (2014) 442-452.

[9] J.S. Ding, W.Q. Hua, H.K. Zhang and Y. Lou, The development and application of two chlorine recycling technologies in polyurethane industry. J. Clean. Prod. 41 (2013) 97-104.

[10] F. Esther, P. Rafaela and R. Jesús, Optimal green tax reforms yielding double dividend. Energy Policy 39 (2011) $4253-4263$.

[11] G. Ferrer and J.M. Swaminathan, Managing new and remanufactured products. Manage. Sci. 52 (2006) 15-26.

[12] G. Ferrer and J.M. Swaminathan, Managing new and differentiated remanufactured products. Eur. J. Oper. Res. 203 (2010) $370-379$

[13] J. Gao, Z. Xiao, H. Wei and G. Zhou, Active or passive? Sustainable manufacturing in the direct-channel green supply chain: A perspective of two types of green product designs. Transp. Res. Part D-Transp. Environ. 65 (2018) 332-354.

[14] A. Gehin, P. Zwolinski and D. Brissaud, A tool to implement sustainable end-of-life str-ategies in the product development phase. J. Clean. Prod. 16 (2008) 566-576.

[15] V.D.R. Guide and L.N.V. Wassenhove, Managing product returns for remanufacturing. Prod. Oper. Manag. 10 (2001) $142-155$.

[16] A. Hafezalkotob, Competition of two green and regular supply chains under environmental protection and revenue seeking policies of government. Comput. Ind. Eng. 82 (2015) 103-114.

[17] E. Haites, Carbon taxes and greenhouse gas emissions trading systems: what have we learned?. Clim. Policy 18 (2018) 955-966.

[18] D. Hammond, P. Beullens, Closed-loop supply chain network equilibrium under legislation. Eur. J. Oper. Res. 183 (2007) $895-908$.

[19] J. Li, W.H. Du, F.M. Yang and G.W. Hua, The carbon subsidy analysis in remanufacturing closed-loop supply chain. Sustainability 6 (2014) 3861-3877.

[20] F. Li, X. Ma, J. Hong and C. Ye, Pricing decision research of closed-loop supply chain under asymmetric information on government regulation. Chin. J. Manag. Sci. 27 (2019) 116-126 (In Chinese).

[21] B.Q. Lin and X.H. Li, The effect of carbon tax on per capita CO2 emissions. Energy Policy 39 (2011) 5137-5146.

[22] K.N. Liu and H.M. Song, Screening contract design for innovative product R\&D outsourcing under asymmetric information. Chin. J. Manag. Sci. 22 (2014) 52-58 (In Chinese).

[23] Z.B. Liu, R.Q. Zhao, X.Y. Liu and L. Chen, Contract designing for a supply chain with uncertain information based on confidence level. Appl. Soft Comput. 56 (2017) 617-631.

[24] S. Mitra and S. Webster, Competition in remanufacturing and the effects of government subsidies. Int. J. Prod. Econ. 111 (2008) 287-298.

[25] K.S. Moorthy, Product and price competition in a duopoly. Mark. Sci. 7 (1988) 141-168.

[26] S.K. Mukhopadhyay, X. Su and S. Ghose, Motivating retail marketing effort: Optimal contract design. Prod. Oper. Manag. 18 (2009) 197-211.

[27] R. Pal and B. Saha, Pollution tax, partial privatization and environment. Resour. Energy Econ. 40 (2015) $19-35$.

[28] R.C. Savaskan, S. Bhattacharya, L.N.V. Wassenhove, Closed-loop supply chain models with product remanufacturing. Manag. Sci. 50 (2004) 239-252.

[29] E. Shekarian, A review of factors affecting closed-loop supply chain models. J. Clean. Prod. 253 (2019) 119823.

[30] J.B. Sheu and Y.J. Chen, Impact of government financial intervention on competition among green supply chains. Int. J. Prod. Econ. 138 (2012) 201-213. 
[31] H.P. Tian and C.X. Liu, Bi-objective incentive model in distribution channel under the framework of dual information asymmetry. J. Manag. Sci. China 14 (2011) 34-47 (In Chinese).

[32] N. Wan and D.J. Hong, The impacts of subsidy policies and transfer pricing policies on the closed-loop supply chain with dual collection channels. J. Clean. Prod. 224 (2019) 881-891.

[33] W.B. Wang and Q.L. Da, The decision and coordination under the premium and penalty mechanism for closed-loop supply chain. Chin. J. Manag. Sci. 19 (2011) 36-41 (In Chinese).

[34] Y.X. Wang, X.Y. Chang, Z.G. Chen, Y. Zhong and T. Fan, Impact of subsidy policies on recycling and remanufacturing using system dynamics methodology: a case of auto parts in China. J. Clean. Prod. 74 (2014) 161-171.

[35] W.B. Wang, X.J. Zhao, P. Zhang, Z.Y. Lu, M.B. Cheng, Incentive mechanism of closed-loop supply chain under double information asymmetry. Chi. J. Manag. Sci. 24 (2016) 69-77 (In Chinese).

[36] W.B. Wang, S.Y. Zhou, M. Zhang, H. Sun and L. He, A closed-loop supply chain with competitive dual collection under asymmetric information and reward-penalty mechanism. Sustainability 10 (2018) 21-25.

[37] W.B. Wang, J.F. Ding, Z.H. Wang and Q.L. Da, Reward-penalty mechanism of government for retailer-led closed-loop supply chain under collection responsibility sharing . Chin. J. Manag. Sci. 27 (2019) 127-136 (In Chinese).

[38] B.B.F. Wittneben, Exxon is right: Let us re-examine our choice for a cap-and-trade system over a carbon tax. Energy Policy 37 (2009) 2462-2464.

[39] Z.H. Wu, H. Chen and Q. Zhao, Closed-loop supply chain coordination under asymmetric information and disruptions with buy back contract. Chin. J. Manag. Sci. 21 (2013) 97-106 (In Chinese).

[40] Y.S. Wu, R.H. Lu, J. Yang, R. Wang, H. Xu, C. Jiang and F. Xu, Government-led low carbon incentive model of the online shopping supply chain considering the O2O model. J. Clean. Prod. 279 (2021) 123271.

[41] Z.K. Xiong, K. Wang and Y. Xiong, Closed-loop supply chain considering that the distributor engages in remanufacturing . J. Syst. Eng. 26 (2011) 792-800 (In Chinese).

[42] H. Xu, G.H. Shi and W.W. Gong, Principal-agent-based recycling incentive mechanism with double information asymmetry. Ind. Eng. J. 15 (2012) 53-57 (In Chinese).

[43] Y. Yu and T.D. Jin, The return policy model with fuzzy demands and asymmetric information. Appl. Soft Comput. 11 (2011) $1669-1678$.

[44] Q.H. Zhang and J.W. Luo, Coordination of supply chain with trade credit under bilateral information asymmetry. Syst. Eng. Theory Pract. 29 (2009) 32-40.

[45] H. Zhang and J.L. Jing, The government incentive regulation model and pricing mech- anism in power transmission and distribution market. Discrete Dyn. Nat. Soc. (2016) 1-9.

[46] Z.Y. Zhang, Y.H. Chen and Y.J. Liu, Research on coordination mechanism of remanufacturing closed-loop supply chain under government subsidy based on differential pricing. Math. Pract. Theory 49 (2019) 53-63 (In Chinese).

[47] H. Zhang, X.X. Xu, J.L. Jiang and M. Zhang, Carbon tax and trading price on power plant with carbon capture and storage under incentive regulation theory. Discrete Dyn. Nat. Soc. (2020) 1-12.

[48] X.D. Zhu, Z. Wang, Y. Wang and B. Li, Incentive policy options for product remanufacturing: subsidizing donations or resales?. Int. J. Environ. Res. Public Health 14 (2017) 1496.

\section{Subscribe to Open (S2O) A fair and sustainable open access model}

This journal is currently published in open access under a Subscribe-to-Open model (S2O). S2O is a transformative model that aims to move subscription journals to open access. Open access is the free, immediate, online availability of research articles combined with the rights to use these articles fully in the digital environment. We are thankful to our subscribers and sponsors for making it possible to publish this journal in open access, free of charge for authors.

\section{Please help to maintain this journal in open access!}

Check that your library subscribes to the journal, or make a personal donation to the $\mathrm{S} 2 \mathrm{O}$ programme, by contacting subscribers@edpsciences.org

More information, including a list of sponsors and a financial transparency report, available at: https://www. edpsciences.org/en/maths-s2o-programme 